\title{
An Interesting Relationship Between Squares and Hex Numbers
}

\section{Günhan Caglayan}

Proposition. Let $h_{n}$ stand for the nth hexagonal number. Then for $n \in \mathbb{N}$, the following identity bolds:

$$
h_{3 n-2}=6 h_{n}+1 h_{n-1}+6(n-1)^{2}-6 n
$$

Proof. The proof is demonstrated for $n=5$.

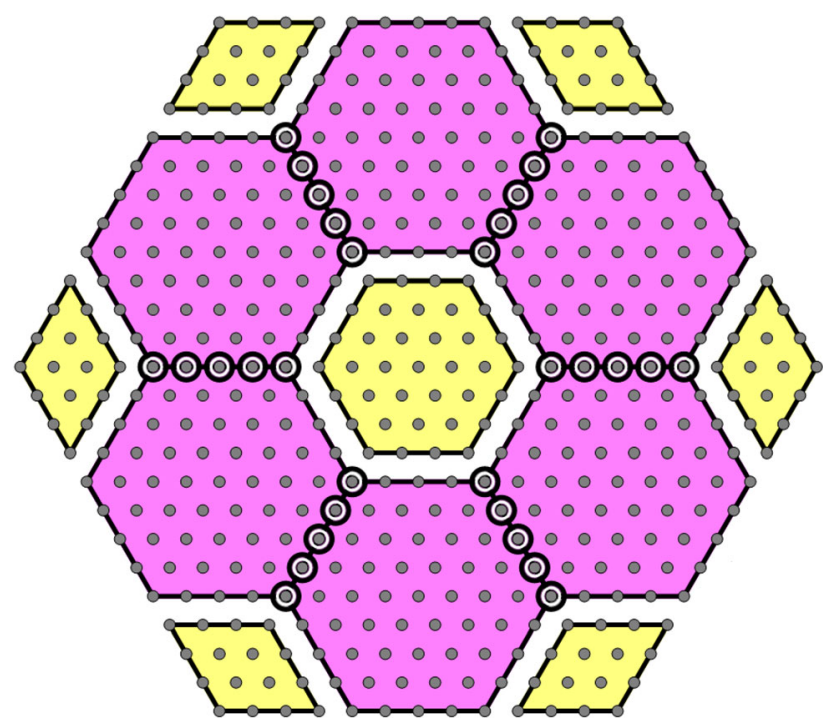

Günhan Caglayan

Mathematics Department

New Jersey City University Jersey City, NJ 07305

USA

e-mail: gcaglayan@njcu.edu

Publisher's Note Springer Nature remains neutral with regard to jurisdictional claims in published maps and institutional affiliations. 